\title{
The Atomizer Sign: A Diagnostic Clue to Fragrance Allergic Contact Dermatitis
}

\author{
Eduardo Rozas-Muñoz ${ }^{1}$, Jaime Piquero-Casals², Juan-Francisco Mir-Bonafé ${ }^{3}$
}

1 Department of Dermatology, Hospital San Pablo, Coquimbo, Chile

2 Department of Dermatology, Clínica dermatológica multidisciplinar Dermik, Barcelona

3 Department of Dermatology, Hospital Son Llàtzer, Palma de Mallorca, Spain

Key words: Allergic contact dermatitis, fragrances, neck

Citation: Rozas-Muñoz E, Piquero-Casals J, Mir-Bonafé JF. The atomizer sign: a diagnostic clue to fragrance allergic contact dermatitis. Dermatol Pract Concept. 2021; 11(3): e2021041. DOI: https://doi.org/10.5826/dpc.1103a41

Accepted: November 12, 2020; Published: July 8, 2021

Copyright: $\odot 2021$ Rozas-Muñoz et al. This is an open-access article distributed under the terms of the Creative Commons Attribution License BY-NC-4.0, which permits unrestricted noncommercial use, distribution, and reproduction in any medium, provided the original authors and source are credited

Funding: None

Competing interests: None

Authorship: All authors have contributed significantly to this publication

Corresponding author: Eduardo Rozas-Muñoz, MD. Department of Dermatology, Hospital San Pablo, Avenida Videla S/N, 1780000 -Coquimbo. Chile. EMail: docrozas@yahoo.com

\section{Case Report}

A 63-year-old man presented with pruritic and well-defined erythematous and vesicular eczematous plaques involving the anterior aspect of the neck and chest, present for the last 3 months (Figure 1). The rest of the physical examination was unremarkable, and there was no past or family history of seborrhea or psoriasis. The patient was treated with topical corticosteroids showing some improvements, but with frequent relapses. Patch test with Thin-Layer Rapid Use (T.R.U.E.) Epicutaneous Patch Test ${ }^{\mathrm{TM}}$ revealed a positive $(+++)$ reaction to fragrance mix I. The patient was therefore instructed to avoid fragrance-containing products showing complete improvement of his dermatitis.

\section{Teaching Point}

The presence of an eczematous dermatitis on the anterior neck in the Adam's apple region has been referred to as the atomizer sign, being a common area of application of aerosol

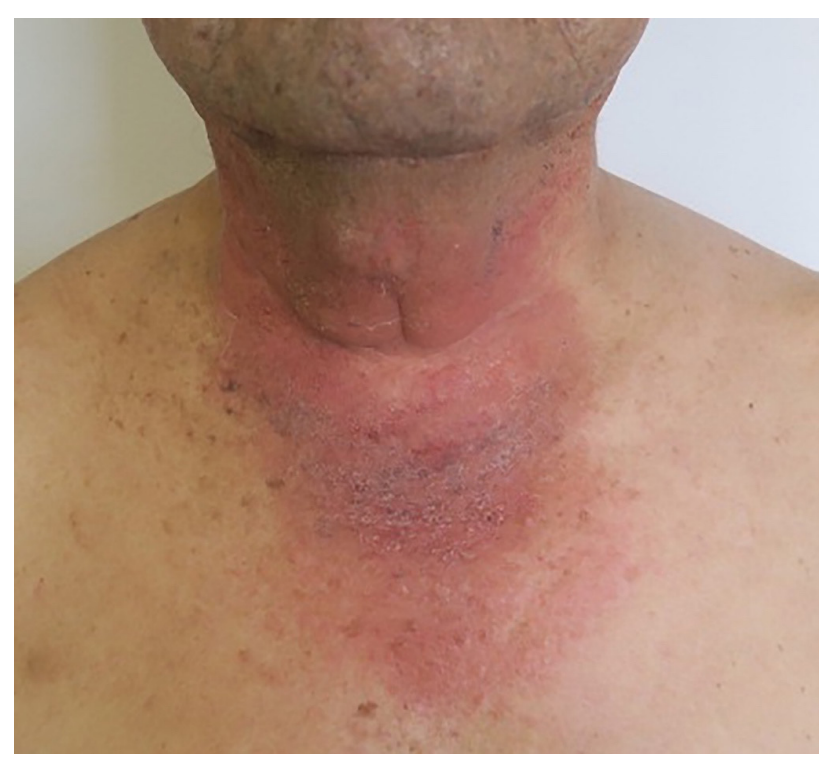

Figure 1. Eczematous plaques involving the anterior aspect of the neck (Adam's apple region) and "V" of the anterior chest. 
perfumes or cologne [1]. Patients with this peculiar presentation should be patch tested to rule-out any allergic contact dermatitis to fragrances.

\section{References:}

1. Sharon E Jacob, Mari Paz Castanedo-Tardan. A diagnostic pearl in allergic contact dermatitis to fragrances: the atomizer sign. Cutis. 2008;82(5):317-318. PMID: 19090333. 